\title{
A study of the Association of Metabolic Syndrome to Polycystic Ovarian Syndrome (PCOS)
}

\author{
Dr. Gurindapalli Jyothi Swarna Laya Latha*1, Dr. Matta Sreevani ${ }^{2}$, \\ Dr. Chandrakala ${ }^{3}$, Dr. Bezawada Srinivasa Rao ${ }^{4}$ \\ ${ }^{I}$ Assistant Professor, Department of Biochemistry, Siddhartha Medical College, NTRUHS, Vijayawada, India. \\ ${ }^{2}$ Assistant Professor, Department of Biochemistry, SMC, NTRUHS, Vijayawada, India. \\ ${ }^{3}$ Associate Professor, Department of Pharmacology, SMC, NTRUHS, Vijayawada, India. \\ ${ }^{4}$ Associate Professor, Department of Medicine, Govt. General Hospital, SMC, NTRUHS, Vijayawada, India.
}

\begin{abstract}
Polycystic ovarian syndrome is the most common form of anovulatory infertility. ${ }^{-}$The aetiology of the condition is unknown, but recent evidence suggests that the principal underlying disorder is insulin resistance, with the resultant hyperinsulinaemia stimulating excess ovarian androgen production. Associated with the prevalent insulin resistance, these women exhibit a characteristic dyslipidaemia and a predisposition to non-insulin dependent diabetes and cardiovascular disease in later life. Thus, polycystic ovarian syndrome seems to have many of the hallmarks of the metabolic syndrome. In view of this a comparative study of lipid profile was done in primary infertile women with PCOD and primary infertile women with normal pelvic study. This study enrolled 25 PCOD women and 25 normal women of age 20 - 35 years.

Pearsons correlation co efficiencies were used to compare the correlations. It showed significant raise in waist circumference, fasting blood glucose level in women with PCOD than in women with normal study (controls). This study showed significant raise in total cholesterol, triglycerides and raise in ratio of TTG/HDL-C, decrease in levels of HDL-C in PCOD women.
\end{abstract}

Key words: Hyperinsulinaemia, lipid profile, cardiovascular accidents, waist circumference, sex hormone binding globuline (androgen).

\section{Introduction}

Polycystic ovarian syndrome is the most common form of anovulatory infertility. ${ }^{1}$ The, polycystic ovarian syndrome seems to have many of the hallmarks of the metabolic syndrome. It is evident that polycystic ovarian syndrome should no longer be considered a purely gynaecological disorder. Affected women seem to have subclinical insulin resistance and a form of the metabolic syndrome that manifests itself in early adult life with gynaecological symptoms. They may therefore gain particular benefit from early screening for metabolic syndrome. ${ }^{2}$ Along with racial variations; the prevalence of the condition can only be estimated between $5 \%$ and $10 \%$ of women of reproductive age. ${ }^{3}$

The aetiology of polycystic ovarian syndrome is uncertain. There is some evidence of autosomal transmission related to strong familial clustering. Potentially, a gene or series of genes renders the ovaries susceptible to insulin stimulation of androgen secretion while blocking follicular maturation. ${ }^{4}$ The onset may occur in late childhood since many of the metabolic and endocrine features of the disorder mimic puberty. Associated with this are increases in the pulse amplitude of luteinising hormone, increasing androgen concentrations, and irregular menses. Multiple, small ovarian cysts are seen on ultrasound examination are a common and normal feature of poly cystic ovarian syndrome. Good evidence supports the hypothesis that decreased peripheral insulin sensitivity and consequent hyperinsulinaemia are pivotal in the pathogenesis of polycystic ovarian syndrome.

Despite insulin resistance in adipose and skeletal muscle, the ovary remains relatively sensitive to insulin, and both insulin and insulin-like growth factor 1 have stimulatory effects on thecal androgen production 5 Figure 1 shows how the relative excess of insulin or enhanced ovarian sensitivity to insulin, in combination with an elevated luteinising hormone concentration, brings about thecal hyperplasia, increased androgen secretion, arrest of follicular development, and therefore anovulation along with menstrual disturbance. 


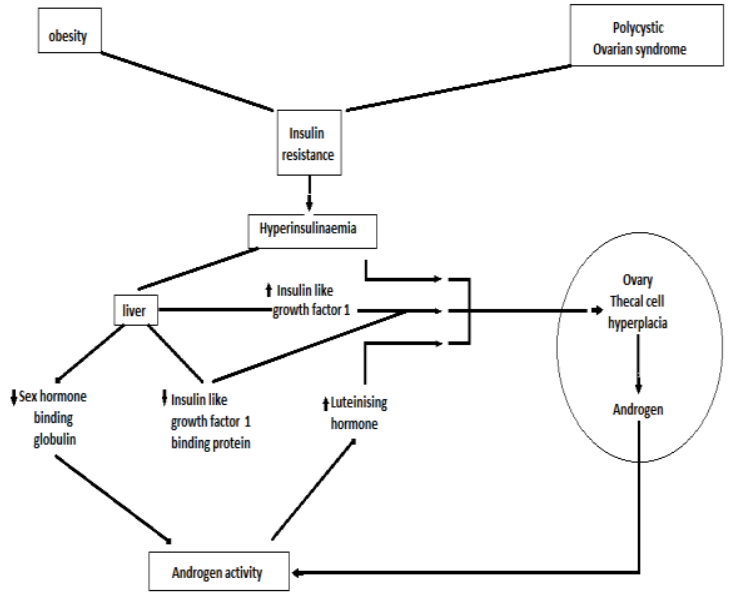

Fig.1. Probable mechanisms whereby defects in insulin metabolism promote increased androgen activity at the level of the ovary

Insulin also acts on the liver to inhibit the production of sex hormone binding globulin and insulin-like growth factor 1 binding protein. A reduction in sex hormone binding globulin leads to an increase in the biologically available free testosterone. Thus, insulin resistance not only increases secretion of ovarian androgens but also promotes an increase in the proportion of free (active) hormone. Similarly, inhibition of production of insulin-like growth factor 1 binding protein results in an increased concentration of circulating free insulin-like growth factor 1 , further enhancing ovarian androgen production ${ }^{6}$

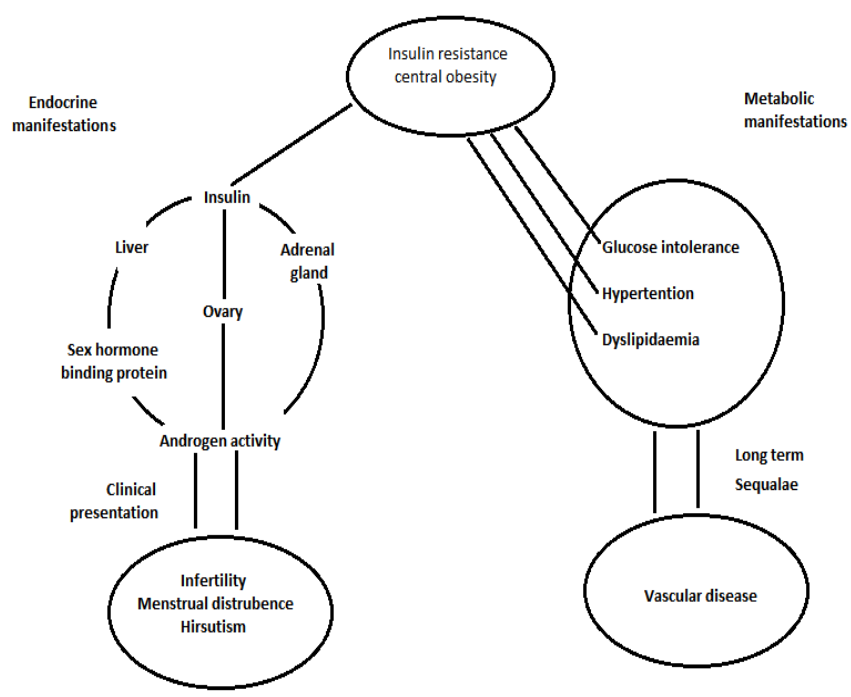

Fig 2. Central role of insulin resistance in both the clinical presenting features and long term sequelae of polycystic ovarian syndrome

Figure 2 shows the principal features of the polycystic ovarian syndrome. It is well recognised that visceral distribution of body fat, common in the syndrome, is of greater consequence to the metabolic effects of insulin resistance than obesity per se. ${ }^{7}$ Central obesity and insulin resistance lead to an altered lipolytic response to insulin, with impaired suppression of release of free fatty acids from adipose tissue. An increased flux of free fatty acids from central sites enters the portal circulation, increasing the availability of substrate to the liver for VLDL-Triglyciride production. Furthermore, women with the syndrome exhibit increased activity of hepatic lipoproteinlipase, an enzyme responsible for the conversion of large lipoprotein particles to smaller, more atherogenic species. This explains the findings of reduced concentrations of high density lipoprotein cholesterol and increased levels of atherogenic, small, low density lipoprotein. ${ }^{8}$

The combination of raised triglyceride and decreased high density lipoprotein is strongly linked with cardiovascular disease. ${ }^{9}$ Discrepancies in these lipid parameters between patients with polycystic ovarian 
syndrome and controls matched for age and weight are evident at an early age. Hence, an increased risk of cardiovascular disease due to lipid perturbances will present in early adult life. Women with polycystic ovarian syndrome also show elevated concentrations of plasminogen activator inhibitor $1,{ }^{10}$ a potent inhibitor of fibrinolysis, which have been shown to predict the, occurrence of myocardial infarction. Important retrospective studies provide evidence of increased risk of cardiovascular disorders. A study of women thought to have polycystic ovarian syndrome who were treated with ovarian wedge resection 20-30 years earlier showed that they were four times more likely to be receiving treatment for hypertension than age and weight matched controls and seven times more likely to have a diagnosis of diabetes. ${ }^{11}$

Models using triglyceride concentrations, waist to hip ratio, non-insulin dependent diabetes, and elevated blood pressure in women with polycystic ovarian syndrome indicate a 7.4-fold increased risk of myocardial infarction compared with age matched referents. ${ }^{2}$ As per revised consensus was made to screen all obese women with PCOS for Metabolic Syndrome (MBS) $\stackrel{12}{\text {. }}$.

\section{Criteria used to define metabolic syndrome:}

Most widely adapted are the criteria proposed by the American National Cholesterol Education Program (NCEP)_Adult Treatment Panel III(ATP-III)) ${ }^{13}$. These criteria require the presence of 3 of 5 common CV risk factors (increased waist circumference, blood pressure, elevated fasting blood glucose, low serum highdensity lipoprotein (HDL)-cholesterol, and increased triglycerides). Using these criteria, the prevalence in PCOS has been reported to be extremely rhigh, $43-46 \% \frac{14}{4}$, primarily on the basis of abnormal lipids and increased waist circumference.

\section{Aim of Present Study}

Polycystic ovary syndrome (PCOS) is one condition commonly detected in a younger age group and associated with a high risk of progression to diabetes. Interestingly, many of the features of the metabolic syndrome, including insulin resistance, obesity, and dyslipidemias, are also present in PCOS. It is evident that polycystic ovarian syndrome should no longer be considered a purely gynaecological disorder. Affected women seem to have subclinical insulin resistance and a form of the metabolic syndrome that manifests itself in early adult life with gynaecological symptoms. They may therefore gain particular benefit from early screening for cardiovascular risk factors. Cardiovascular disease (CVD) is the number-one cause of death among patients with diabetes, and its prevention is at the forefront of modern diabetes care. Current study is aimed at establishing the relation between PCOS and Metabolic Syndrome

1.To compare the blood sugar,blood pressure and waistcircumference in pcos with control group.

2.To compare lipid profile in pcos with control group.

\section{Materials \& methods}

This study was conducted at Govt. General Hospital and Siddhartha Medical College, on 50 subjects, out of them 25 were primary infertile women with PCOD. 25 Were primary infertile women with normal pelvic study of age group $20-35$ yrs. This study was approved by institutional ethics committee. Written informed consent was taken from the patients in local language. This is an observational and comparative study.

\section{Inclusion Criteria:}

1. Age group $20-35$ years: Primary infertile women.

2. Patients with central obesity.

3. Patients with primary infertility supportive evidence with ultra sound report.(Bilateral multiple ovarian cysts)

\section{Exclusion criteria:}

Patients who were diabetic and hypertensive, excluded from the study.

\section{Investigations:}

Age, height, weight, waist circumference and blood pressure were recorded.

Collection of blood samples: $5 \mathrm{ml}$ of venous blood was collected in heparinised bottle after an overnight fast of $12 \mathrm{hrs}$. Serum was separated and the following parameters were estimated.

1. Estimation of Fasting blood sugar by $\underline{15}$

2. Estimation of total cholesterol by CHOD-PHOD/phosphor tungstate method of Alliance $\frac{16}{}$

3. Estimation of High Density Lipoprotein (HDL) cholesterol by CHOD - POD phosphotungstate method by Burstein $\frac{17}{17}$

4. Estimation of triglycerides by glycerol phosphate oxidase method of Jacobe 18

5. TTG/HDL-C ratio is caliculated. 
Statistical analysis: Pearsons correlation co efficiencies were used to compare the correlations.

\section{Results}

This study was initiated in December 2012 and completed in November 2013 at Government General Hospital and Siddhartha Medical College, Vijayawada, Andhra Pradesh, India.

\section{Comparative Table No - 1: Controls to PCOS}

\begin{tabular}{|c|c|c|c|}
\hline Parameters & $\begin{array}{c}\text { Control } \\
\mathrm{M}( \pm \text { S.D })\end{array}$ & $\begin{array}{c}\text { PCOS } \\
\mathrm{M}( \pm \mathrm{S} . \mathrm{D})\end{array}$ & $\begin{array}{c}\text { P value } \\
\text { Significance }\end{array}$ \\
\hline $\begin{array}{c}\mathrm{FBG} \\
(\mathrm{mg} \%)\end{array}$ & $84.84( \pm 5.17)$ & $101.36( \pm 10.53)$ & $\begin{array}{c}\mathrm{P}<0.001 \\
\text { Highly significant }\end{array}$ \\
\hline $\begin{array}{c}\text { B.P Systolic/Diastolic } \\
(\mathrm{mmHg})\end{array}$ & $\begin{array}{c}109.2 / 77.8 \\
( \pm 7.44 / \pm 4.35)\end{array}$ & $\begin{array}{c}126 / 84.4 \\
( \pm 13.54 / \pm 5.06)\end{array}$ & $\begin{array}{c}\text { P }<0.001 \\
\text { Highly significant }\end{array}$ \\
\hline $\begin{array}{c}\text { Waist circumference } \\
\text { (inches) }\end{array}$ & $33.36( \pm 1.25)$ & $36.96( \pm 2.95)$ & $\begin{array}{c}\text { P }<0.0001 \\
\text { Highly significant }\end{array}$ \\
\hline
\end{tabular}

In the present study a raise in Fasting Blood Glucose (FBG) level in PCOS with mean and S.D. 101.36 \pm 10.53 compared to controls having mean and S.D. $84.84 \pm 5.17$ is Highly Significant $(\mathrm{P}<0.001)$.

A raise in systolic blood pressure in PCOS with mean and S.D. is $126 \pm 13.54$ compared to controls having mean and S.D. $109.2 \pm 7.44$ is Highly Significant $(\mathrm{P}<0.001)$.

A raise in diastolic blood pressure in PCOS with mean and S.D. is $84.4 \pm 5.06$ compared to controls having mean and S.D. $77.6 \pm 4.35$ is Highly Significant $(\mathrm{P}<0.001)$.

\section{Comparative Table No - 2: Controls to PCOS}

\begin{tabular}{|c|c|c|c|}
\hline Parameters & $\begin{array}{c}\text { Control } \\
\mathrm{M}( \pm \text { S.D })\end{array}$ & PCOS & $\begin{array}{c}\text { P value } \\
\text { Significance }\end{array}$ \\
\hline $\begin{array}{c}\text { Total Cholesterol } \\
(\mathrm{mg} \%)\end{array}$ & $\begin{array}{l}197.12 \\
( \pm 7.41)\end{array}$ & $\begin{array}{c}200.12 \\
( \pm 11.76)\end{array}$ & $\begin{array}{c}\mathrm{P}<0.05 \\
\text { Significant }\end{array}$ \\
\hline $\begin{array}{l}\text { Total Triglycerides } \\
(\mathrm{mg} \%)\end{array}$ & $\begin{array}{l}134.48 \\
( \pm 9.00)\end{array}$ & $\begin{array}{l}157.68 \\
( \pm 6.33)\end{array}$ & $\begin{array}{c}\quad \mathrm{P}<0.001 \\
\text { Highly significant }\end{array}$ \\
\hline $\begin{array}{c}\text { High Density } \\
\text { Lipoprotein Cholesterol } \\
\text { (HDL-C) } \\
(\mathrm{mg} \%)\end{array}$ & $\begin{array}{c}49.68 \\
( \pm 3.11)\end{array}$ & $\begin{array}{c}43.38 \\
( \pm 3.29)\end{array}$ & $\begin{array}{l}\quad \mathrm{P}<0.001 \\
\text { Highly significant }\end{array}$ \\
\hline
\end{tabular}

A raise in Total Cholesterol in PCOS with mean and S.D. $200.12 \pm 11.76$ compared to controls having mean and S.D. $197.12 \pm 7.41$ is Significant $(\mathrm{P}<0.05)$.

A raise in Total triglycerides in PCOS with mean and S.D. $157.68 \pm 6.33$ compared to controls having mean and S.D. $134.48 \pm 9.00$ is Highly Significant $(\mathrm{P}<0.001)$.

A raise in High Density Lipoprotein Cholesterol (HDL-C) in PCOS with mean and S.D. $43.38 \pm 3.29$ compared to controls having mean and S.D. $49.68 \pm 3.11$ is Highly Significant $(\mathrm{P}<0.001)$. 


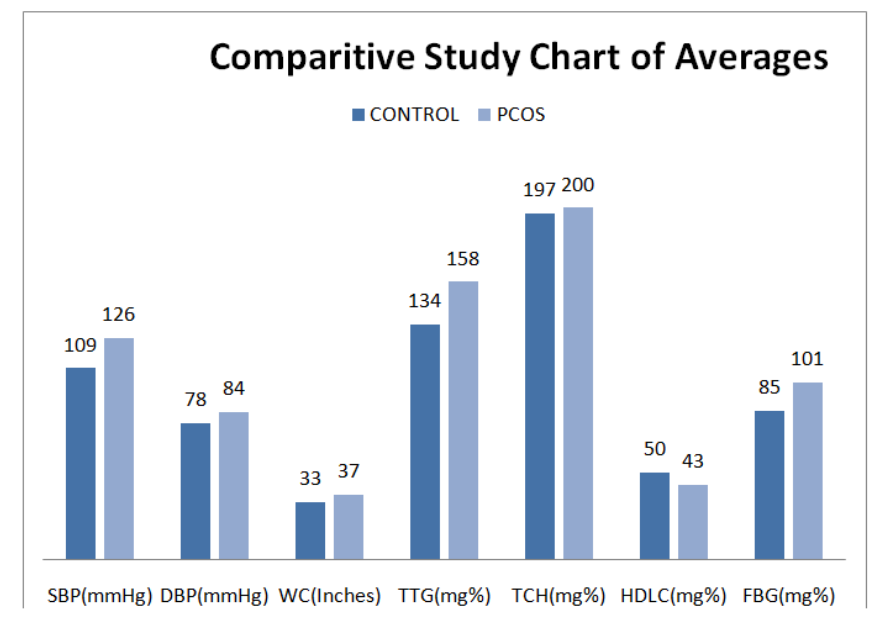

\section{Discussion}

In our study women with abdominal obesity i.e., increased waist circumference $(>35$ inches) and ultra-sound findings are taken as identifiable factors for detecting PCOS cases. Ultra-sound findings are similar in women with abdominal obesity and in a smaller group of lean patients with PCOS. ${ }^{19}$ Although categorical abdominal obesity (waist circumference $>35$ inches) is most strongly associated with metabolic syndrome, it is supported by the World Health Organization clinical criteria for metabolic syndrome used BMI more than 30 or waist/hip ratio interchangeably. ${ }^{20}$ Our findings regarding waist circumference are similar to the study of Glueck CJ, Papanna R about prevalence of metabolic syndrome in women with PCOS reported, using abdominal waist circumference. ${ }^{21}$

The results of our study indicate that women with PCOS are strongly associated with metabolic syndrome compared with age-matched, contemporary controls. Similar studies showed an increased risk of 11 fold increase of metabolic syndrome in women with PCOS compared with age matched contemporary controls as per NHANES III ( $3^{\text {rd }}$ National Health and Nutrition Examination Survey study)..$^{22}$ Although the clustering of components of metabolic syndrome significantly increases morbidity and mortality, each component is also independently atherogenic. ${ }^{23}$ In our study, abnormalities in HDL-C, and triglycerides (dyslipidemia) were detected in women with PCOS. These findings are supported by the study of Legro RS, Kunselman AR, prevalence and predictors of dyslipidemia in women with poly cystic ovarian syndrome.$^{24}$ High triglycerides and low HDL-C levels are independent predictors of myocardial infarction and cardiovascular disease, supported by study of Gaziano JM, Hennekens CH, fasting triglycerides, high-density lipoprotein, and risk of myocardial infarction. ${ }^{25}$

Increased triglycerides/HDL-C ratio is also a marker for atherogenesis with small, dense LDL particles. It has been suggested that a triglycerides/HDL-C ratio may be used as a simple metabolic marker to identify overweight individuals who are insulin-resistant. In a study the findings revealed that triglycerides/HDL-C more than 3.2 had high sensitivity and specificity, suggesting the possible use of this cut off to screen for metabolic syndrome. This finding is not surprising because triglycerides/HDL-C, more than 3 has a high positive predictive value for detecting insulin resistance in overweight/obese patients, ${ }^{-}$and correlates with insulin resistance in severely obese, non diabetic individuals. $\frac{26}{}$

The results of current study indicate the need for a comprehensive screening and education program for women of all ages with PCOS. This study suggests that all patients with PCOS should also be assessed for the presence of metabolic syndrome. Based on current data, only obese women with PCOS may need to be screened at frequent intervals. The triglycerides/HDL-C ratio appears to be a relatively simple test associated with insulin resistance in women with PCOS. Several studies have demonstrated that the progression of metabolic syndrome is attributable to dietary factors and activity levels. ${ }^{27}$

\section{Summary \& conclusion}

The association of polycystic ovarian syndrome to metabolic syndrome which is strongly related to obesity and chronic hyperinsulineamia is well established after NCEP-ATP III. PCOS presents with overt symptoms of infertility, hirsutism, and acne. In the present study most of the women showing more than three risk factors out of five risk factors of metabolic syndrome. Risk factors may not always progresss to disease. Treatment of the individual components of the syndrome, including dyslipidemia, obesity, and hypertension, clearly decrease the incidence of CVD. Therefore, the apptoach requires emphasis on the modification of lifestyle factors such as diet and exercise to modify risk factors in preventing clinical disease. 
Women with PCOS should be informed of their long - term risk of type 11 DM and likely cardiovascular disease. Healthcare providers should educate women with PCOS regarding tranquil life style with an appropriate diet and exercise program. Early pharmacotherapy with insulin sensitisers and lipid lowering agents may be considered if therapeutic life style changes are unsuccessful.

\section{References}

[1]. Frank S. Polycystic ovary syndrome. N Engl J Med 1995; 333: 853-861

[2]. Dahlgren E, Janson PO, Johansson S, Lapidus L, Oden A. Polycystic ovary syndrome and risk for myocardial infarction: evaluated from a risk factor model based on a prospective study of women. Acta Obstet Gynecol Scand 1992; 71: 599-604.

[3]. Dunaif A. Insulin resistance and the polycystic ovarian syndrome: mechanisms and implications for pathogenesis. Endocr Rev 1997;18: 774-800.

[4]. Nestler JE. Insulin regulation of human ovarian androgens. Hum Reprod 1997; 12(suppl): 52-62.

[5]. Bergh C, Carlsson B, Olsson JH, Selleskog U, Hillensjo T. Regulation of androgen production in cultured human thecal cells by IGF-1 and insulin.Fertil Steril 1993; 59: 323-331

[6]. Cataldo NA. Insulin like growth factor binding proteins: do they play a role in polycystic ovary syndrome? Endocrinology 1997; 15: 123-136.

[7]. Douchi T, Ijuin H, Nakamura S, Oki T, Yamamoto S, Nagata Y. Body fat distribution in women with polycystic ovary syndrome. Obstet Gynecol 1995; 86: 516-519.

[8]. Pirwani I, Sattar N, Packard CJ, Wallace AM, Fleming R, Greer IA. Lipoprotein subfraction changes in women with oligomenorrhea: relationship to metabolic, hormonal and anthropometric indices. J Soc Gynecol Invest1997; 4(suppl): 90A.

[9]. Wild R. Metabolic aspects of polycystic ovary syndrome. Semin Reprod Endocrinol 1997; 15: 105-110.

[10]. Velazquez EM, Mendoza SG, Wang P, Glueck CJ. Metformin therapy is associated with decrease plasma plasminogen activator inhibitor-1, lipoprotein (a), and immunoreactive insulin levels in patients with polycystic ovary syndrome. Metabolism 1997; 46: 454-457.

[11]. Dahlgreen E, Johansson S, Lindstedt G, Knutsson F, Oden A, Janson PO, et al. Women with polycystic ovary syndrome wedge resected in 1956 to 1965: a long-term follow-up focusing on natural history and circulating hormones. Fertil Steril 1992; 57: 505513.

[12]. Rotterdam ESHRE/ASRM-Sponsored PCOS Consensus Workshop Group Revised 2003 consensus on diagnostic criteria and long-term health risks related to polycystic ovary syndrome. Fertility and Sterility 200481 19-25.

[13]. Executive Summary of the Third Report of the National Cholesterol Education Program (NECP), Expert Panel on Detection, Evaluation and Treatment of High Blood Cholesterol in Adults (Adult Treatment Panel III). Journal of the American Medical Association $20012852486-2497$.

[14]. Apridonidze T, Essah P, Iuorno M \& Nestler JE. Prevalence and characteristics of metabolic syndrome in women with polycystic ovary syndrome.Journal of Clinical Endocrinology and Metabolism 200590 1929-1935.

[15]. Tietz N W.Fundamentals of clinical chemistry $2^{\text {nd }}$ edition W.B.Sunders co; Toranto (1982)

[16]. Allain C. C. Clinichem 20,470(1974)

[17]. Bustein, M. Etal (1970) J. Lipid res. 17:583

[18]. Jacobe, N. J.,Van Demark, P. J. (1960) Arch Biochem. Biophys. 88,250

[19]. Faloia E, Canibus P, Gatti C, Frezza F, Santangelo M, Garrapa GG, et al. Body composition, fat distribution and metabolic characteristics in lean and obese women with polycystic ovary syndrome. J Endocrinol Invest 2004; 27:424-9.

[20]. World Health Organization. Definition, diagnosis and classification of diabetes mellitus and its complications: report of a WHO consultation. Part 1: diagnosis and classification of diabetes mellitus. Geneva (Switzerland): World Health Organization; 1999.

[21]. Glueck CJ, Papanna R, Wang P, Goldenberg N, Sieve-Smith L. Incidence and treatment of metabolic syndrome in newly referred women with confirmed polycystic ovary syndrome. Metabolism 2003; 52:908-15.

[22]. Ford ES, Giles WH, Dietz WH. Prevalence of metabolic syndrome among US adults: findings from the third National Health and Nutrition Examination Survey. JAMA 2002;287:356-9.

[23]. Hu G, Qiao Q, Tuomilehto J, Balkau B, Borch-Johnsen K, Pyorala K. Prevalence of the metabolic syndrome and its relation to allcause and cardiovascular mortality in nondiabetic European men and women. Arch Intern Med 2004;164:1066-76.

[24]. Legro RS, Kunselman AR, Dunaif A. Prevalence and predictors of dyslipidemia in women with polycystic ovary syndrome. Am J Med 2001;111:607-13.

[25]. Gaziano JM, Hennekens CH, O’Donnell CJ, Breslow JL, Buring JE. Fasting triglycerides, high-density lipoprotein, and risk of myocardial infarction. Circulation 1997; 96:2520-5

[26]. Brehm A, Pfeiler G, Vierhapper H, Roden M. Relationship between serum lipoprotein ratios and insulin resistance in obesity, Clin Chem 2004; 50:2316-22.

[27]. Barnard RJ, Wen SJ. Exercise and diet in the prevention and control of the metabolic syndrome. Sports Med 1994;18:218-28. 